\title{
Pengaruh Kepuasan Kerja dan Komitmen Organisasi terhadap Turnover Intention
}

\author{
Adi Irawan Setiyanto ${ }^{1)}$, Selvi Nurul Hidayati ${ }^{2)}$ \\ 1) Staf Pengajar,Politeknik Negeri Batam, Batam 29461, email: adiirawan@ polibatam.ac.id \\ 2) JurusanManajemen Bisnis,Politeknik Negeri Batam, Batam 29461, email: selvinurul25@ gmail.com
}

\begin{abstract}
Abstrak
Turnover intention merupakan suatu hal yang tidak dapat dihindari oleh suatu perusahaan dan sangat merugikan perusahaan karena banyak waktu serta biaya yang terbuang untuk menyeleksi dan mentraining karyawan baru. Berdasarkan hal tersebut, maka peneliti merasa perlu untuk mengembangkan penelitianpenelitian sebelumya, sehingga peneliti mengambil tiga variabel yaitu kepuasan kerja, komitmen organisasi dan turnover intention dengan menggunakan 162 kuesioner. Data yang diperoleh diolah dan dianalisis menggunakan alat uji statistik SPSS. Hasil pengujian menunjukkan kepuasan kerja tidak berpengaruh secara signifikan terhadap turnover intention namun komitmen organisasi berpengaruh signifikan terhadap turnover intention. Berdasarkan hasil tersebut maka dapat diambil kesimpulan bahwa turnover intention karyawan dipengaruhi oleh tingkat komitmen organisasinya, oleh karena itu perusahaan harus mempertahankan dan meningkatkan komitmen organisasi karyawannya.
\end{abstract}

Kata Kunci: Kepuasan Kerja, Komitmen Organisasi, Turnover Intention

\begin{abstract}
Turnover is one of the problem can't be avoided all the companies due to those are being affect to company expenses such involve for hiring new manpower and wasting time for. Based on the problem is being faced, The researcher is initiatively to develop a research on previously within three great methods, they are : work satisfaction, organization's commitment and intensity of turnover which is use 162 questioners. The datas have been received from the several people will be analyzed using SPSS statistic measurement. The result show that work satisfaction did not significantly affect to turnover intention .But, organization commitment gives a big deal for turnover intention. So, based on the researching we could make a conclusion for turnover intention was affected how much the company put an effort for the commitment in organization. However the company should keep in maintenance of the commitment in organization and make continuous improvement.
\end{abstract}

Keywords: work satisfaction, organization's commitment, turnover intention

\section{PENDAHULUAN}

Organisasi perlu mengatur sumber daya manusia untuk mencapai tujuannya secara efektif, dengan senantiasa melakukan investasi untuk penerimaan, penyeleksian, dan mempertahankan sumber daya manusia yang potensial agar tidak berdampak pada perpindahan karyawan Anis et al. (2003) dalam jurnal (Putra dan Wibawa, 2015). Karyawan merupakan aset perusahaan yang harus dijaga.Dalam suatu organisasi, perputaran karyawan merupakan hal yang tidak dapat dihindari.Tingkat perputaran karyawan yang tinggi, dapat mengganggu kinerja perusahaan dan merugikan perusahaan, karena telah banyak biaya yang dikeluarkan untuk merekrut dan melatih karyawan baru tersebut.

Penelitian ini penting dilakukan untuk mengetahui sebab tingginya turnover intention di suatu perusahaan, untuk mengurangi biaya serta kerugian yang dialami.Ada banyak faktor yang mempengaruhi turnover intention diantaranya adalah stres kerja, kepuasan kerja, lingkungan kerja, komitmen organisasi, dan lain sebagainya (Sutanto dan Gunawan, 2013).

Turnover karyawan merupakan salah satu aspek penting dalam suatu perusahaan, karena bisa berpengaruh terhadap kinerja dan biaya dalam 
perusahaan tersebut. Terhadap kinerja berarti jika perputaran karyawannya tinggi, maka dapat mengganggu proses kinerja perusahaan. Terhadap biaya, semakin tinggi perputaran karyawan maka semakin tinggi pula biaya yang akan dikeluarkan perusahaan, baik untuk merekrut maupun untuk mentrainingnya.

Untuk itu perusahaan harus mengetahui faktor apa saja yang membuat karyawan ingin berpindah dari perusahaan tersebut. Berdasarkan permasalahan tersebut, maka dapat dirumuskan pertanyaan penelitian sebagai berikut: (a) Bagaimanakah pengaruh antara kepuasan kerja terhadap turnover intention, (b) Bagaimanakah pengaruh antara komitmen organisasi terhadap turnover intention.

\section{KERANGKA TEORI}

\subsection{Kepuasan Kerja}

Kepuasan kerja adalah hasil dari persepsi karyawan mengenai seberapa baik pekerjaan mereka memberikan hal yang dinilai penting (Luthans, 2006). Individu cenderung lebih puas jika kinerjanya dihargai dan diapresiasi oleh perusahaannya selain menumbuhkan motivasi, penghargaan juga akan membuat karyawan merasa bahwa kinerjanya dibutuhkan. Sebaliknya pula jika perusahaan kurang menghargai akan menyebabkan karyawan kurang puas dan memilih untuk meninggalkan perusahaan. Penelitian ini menggunakan Equity Theory, yang dikembangkan oleh Adams tahun 1963, pendahulu dari teori ini adalah Zalzenik tahun 1958 yang dikutip dari Locke (1969). Prinsip dari teori ini adalah bahwa orang akan merasa puas atau tidak puas dengan apa yang mereka dapatkan. Perasaan equity dan inequity atas situasi diperoleh orang dengan cara membandingkan dirinya dengan orang lain yang sekelas, sekantor dan pemerintah dipengaruhi oleh motivasi tergantung pada tingkat keadilan yang diberikan perusahaan. Penelitian ini juga menggunakan Discrepancy Theory yang pertama kali dipelopori oleh Porter (1961), ia mengukur kepuasan kerja seseorang dengan menghitung selisih antara apa yang seharusnya dengan kenyataan yang dirasakan, kemudian Locke (1969) menerangkan bahwa kepuasan kerja seseorang tergantung pada discrepancy antara should be (expectation needs or value) dengan apa yang menurut perasaannya atau persepsinya telah diperoleh melalui pekerjaan.

\subsection{Komitmen Organisasi}

Menurut (Luthans, 2006) mendefinisikan komitmen organisasi sebagai berikut: (1) keinginan kuat untuk tetap sebagai anggota organisasi tertentu, (2) keinginan untuk berusaha keras sesuai keinginan organisasi, (3) keinginan tertentu, dan penerimaan nilai dan tujuan ogansasi. Dapat disimpulkan bahwa komitmen organisasi merefleksi loyalitas karyawan pada organisasi dan proses berkelanjutan dimana anggota organisasi mengekspresikan perhatiannya terhadap organisasi dan keberhasilan serta kemajuan yang berkelanjutan.

Meyer dan Allen, dalam buku (Luthans, 2006) menyebutkan ada tiga dimensi dalam komitmen organisasi, yaitu: (1) Komitmen afektif yaitu keterikatan emosional karyawan, identifikasi dan keterlibatan dalam organisasi. (2) komitmen kelanjutan adalah komitmen berdasarkan kerugian yang berhubungan dengan keluarnya karyawan. Hal ini mungkin karena kehilangan senioritas atas promosi atau benefit. (3) komitmen normatif adalah perasaan wajib untuk tetap berada dalam organisasi karena memang harus begitu (Tindakan tersebut merupakan hal benar yang harus dilakukan).

\subsection{Turnover Intention}

Sikap dapat merupakan suatu perasaan yang tidak disertai oleh kecenderungan untuk berbuat atau bertindak sesuai dengan sikapnya.Selanjutnya sikap diarahkan sebagai kesediaan untuk bereaksi terhadap suatu objek yang dapat berupakan benda, orang, peristiwa, lembaga, nila-nilai, dan sebagainya (Sunyoto, 2015).

Adapun ciri-ciri sikap menurut WA. Gerungan, dalam buku Sunyoto (2015), yaitu:

a. Sikap bukan merupakan bawaan manusia sejak lahir, melainkan dibentuk atau diperoleh sepanjang perkembangan orang itu dalam hubunganya dengan objek tertentu.

b. Sikap dapat berubah-ubah dan dapat dipelajari, oleh karena itu sikap dapat berubah pada orang bila terdapat keadaan dan syarat tertentu yang mempermudah sikapnya pada orang itu sendiri.

c. Sikap itu tidak berdiri sendiri melainkan senantiasa mengandung hubungan pada objek tertentu yang dapat dirumuskan dengan jelas.

d. Sikap mempunyai segi motivasi dan segi perasaan dalam membedakan sikap daripada kecakapan dan pengetahuan yang dimiliki seseorang.

Karakteristik sikap menurut Gitosudarmo, dalam buku Sunyoto (2015), yaitu:

a. Sikap memiliki arah, derajat, dan intensitas

Artinya sikap seseorang terhadap suatu objek akan menunjukkan suatu arah tertentu dari suatu objek. Arah seseorang terhadap suatu objek dapat mendekat atau menjauh.Sikap seseorang itu mempunyai derajat tertentu yaitu sampai berapa tingkat orang merasa senang atau tidak senang terhadap suatu objek, sedangkan intensi sikap seseorang ditunjukkan oleh tingkat pendiriannya.

b. Sikap memiliki struktur

Sikap merupakan kerangka organisasi dari beberapa sikap yang ada pada seseorang, didalamnya terdapat sejumlah sikap yang tergabung membentuk rangkaian yang kompleks. 
c. Sikap selalu memiliki objek

Artinya selalu mempunyai sesuatu hal yang dianggap penting.Objek sikap dapat berupa konsep abstrak seperti konsumerisme atau berupa sesuatu yang nyata.

d. Sikap merupakan proses yang dipelajari

Artinya sikap dibentuk dari pengalaman individu terhadap realitas, dimana pengalaman tersebut dapat bersifat langsung maupun tidak langsung.

Icek Ajzen dan Martin Fishbein dalam Brehm dan Kassin (1990) mengemukakan Teori Tindakan Beralasan (theory of reasoned action) yang menyatakan bahwa sikap mempengaruhi perilaku lewat suatu proses pengambilan keputusan yang teliti dan beralasan dan dampaknya terbatas hanya pada tiga hal ; pertama, perilaku tidak banyak ditentukan oleh sikap umum tapi oleh sikap yang spesifik terhadap sesuatu. Kedua, perilaku dipengaruhi tidak hanya oleh sikap tapi juga oleh norma-norma objektif (subjective norms) yaitu keyakinan kita engenai apa yang orang lain inginkan agar kita perbuat. Ketiga, sikap terhadap suatu perilaku bersama norma-norma subjektif membentuk suatu intensi atau niat berperilaku tertentu. Teori perilaku beralasan diperluas dan dimodifikasi oleh Ajzen (1988) dan dinamai Teori Perilaku Terencana, inti dari teori ini mencakup tiga hal yaitu; keyakinan tentang kemungkinan hasil dan evaluasi dari perilaku tersebut (behavioral beliefs), keyakinan tentang norma yang diharapkan dan motivasi untuk memenuhi harapan tersebut (normative beliefs), serta keyakinan tentang adanya faktor yang dapat mendukung atau menghalangi perilaku dan kesadaran akan kekuatan faktor tersebut (control beliefs) (www.academia.edu).

\subsection{Pengembangan Hipotesis}

Pengaruh kepuasan kerja dan komitmen organisasi Pada dasarnya ketika seseorang telah memutuskan untuk bergabung dengan organisasi tertentu, berarti mereka telah berkomitmen terhadap organisasi tersebut. Seiring berjalannya waktu ketika mereka telah merasakan puas atau tidak puas terhadap pekerjaannya baik dari segi gaji, kondisi kerja ataupun pekerjaan itu sendiri akan mempengaruhi komitmen organisasinya. Seperti penelitian yang telah dilakukan oleh Despandhe et al.(2013) menyebutkan bahwa kepuasan kerja mempunyai pengaruh yang signifikan terhadap komitmen organisasi.

Pengaruh kepuasan kerja dan turnover intention Kepuasan kerja bukan hanya mengurangi stres, tetapi juga dapat membantu meningkatkan kinerja, mengurangi pergantian karyawan dan ketidak hadiran (Luthans, 2006). Kepuasan kerja yang didapat akan menjadikan semangat untuk bekerja sehingga pekerjaan akan menjadi lebih menyenangkan. Hasil penelitian yang dilakukan oleh Applebaum (2008) menunjukkan kepuasan kerja mempunyai hubungan yang signifikan terhadap turnover intention. Hal ini menunjukkan jika kepuasan kerja yang dirasakan tinggi, maka turnover intention akan rendah .

\section{Pengaruh komitmen organisasi dan turnover} intention

Komitmen berkelanjutan mempunyai hubungan dengan turnover intention, karena terkait dengan biaya yang dikeluarkan (Cohen dan Ronit, 2007).Hasil penelitian yang dilakukan oleh Warner (2001) menyatakan bahwa ada hubungan yang positif antara komitmen organisasi dan turnover intention.Artinya jika komitmen tinggi maka turnover intention rendah.

\subsection{Hipotesis}

Kepuasan kerja merupakan perasaan atas hasil dari pekerjaan yang telah dicapai. Menurut hasil penelitian yang dilakukan oleh Mahdi et al (2012) menyatakan bahwa terrdapat hubungan yang kuat antara kepuasan kerja dan turnover intention. Penelitian lain yang dilakukan oleh Gishelle et al (2001) menunjukkan bahwa kepuasan kerja cenderung meningkat jika gaji meningkat. Hal ini sesuai dengan Equity Theory yang menyatakan bahwa kepuasan kerja tergantung pada keadilan yang dirasakan oleh karyawan. Berdasarkan teori dan hasil penelitian sebelumnya, maka diajukan hipotesis sebagai berikut:

\section{H1: Kepuasan kerja memiliki pengaruh terhadap turnover intention.}

Komitmen organisasi adalah keadaan seseorang untuk menilai sejauh mana prinsip dan tujuannya sesuai dengan prinsip dan tujuan perusahaan. Hasil penelitian yang dilakukan oleh Holland (1992) menunjukkan bahwa ada hubungan antara komitmen organisasi terhadap turnover intention. Dari penjelasan tersebut maka diajukan hipotesis sebagai berikut:

H2: Komitmen organisasi memiliki pengaruh terhadap turnover intention.

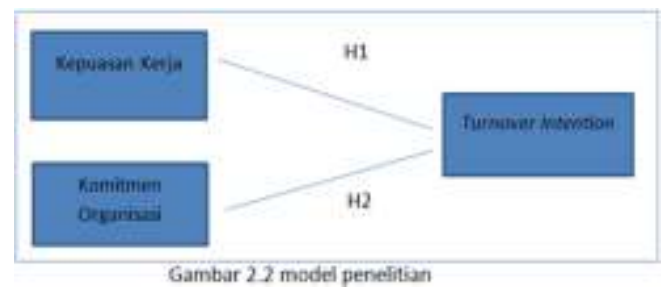

3. METODE PENELITIAN

\subsection{Jenis dan Sumber Data}

Jenis data yang digunakan dalam penelitian ini yaitu data kuantitatif yang berasal dari data sekunder berupa kuesioner.Menggunakan skala Likert 1-5 yang merupakan data ordinal, selanjutnya data ordinal tersebut di ubah menjadi data 
interval.Alasan peneliti menggunakan skala Likert adalah, karena lebih mudah difahami oleh responden, serta tidak memakan banyak waktu untuk menjawabnya.

\subsection{Instrumen Penelitian}

Instrumen penelitian ini menggunakan kuesioner tentang pengaruh kepuasan kerja dan komitmen organisasi terhadap turnover intention karyawan.Kuesioner diambil dari penelitian yang dilakukan oleh (Widyantara, 2015).Kuesioner ini dipilih karena mampu mengidentifikasi variabel variabel yang digunakan.

Kepuasan kerja merupakan variabel independen (X1) yang didalamnya terdiri dari prestasi kerja, pengakuan, penghargaan, tanggung jawab, peluang untuk lebih berkembang.Komitmen organisasi merupakan variabel independen (X2) yang didalamnya terdiri dari loyalitas, ikatan emosional dengan perusahaan.Turnover intention merupakan variabel dependen $(\mathrm{Y})$ yang didalamnya terdiri dari niat untuk keluar, rencana untuk keluar, berusaha mencari pekerjaan baru.

\subsection{Lokasi dan Objek Penelitian}

Lokasi penelitian dilakukan di kota Batam dengan obyek penelitian karyawan yang bekerja pada perusahaan manufaktur di kawasan Panbil kota Batam. Peneliti mengambil lokasi ini dengan pertimbangan efisiensi dan efektivitas waktu yang tersedia.

\subsection{Teknik Penetapan Jumlah Sampel}

Penetapan jumlah sampel dalam penelitian ini yaitu menggunakan tabel Isaac dan Michael. Ketentuan Jumlah Sampel dengan Jumlah Populasi sebanyak 8.000 karyawan dengan Tingkat Kesalahan 5\% diperoleh $\mathrm{S}=334$.

\subsection{Teknik Penarikan Sampel}

Teknik penarikan sampel dalam penelitian ini yaitu menggunakan non random sampling, dimana tidak semua populasi memiliki kesempatan untuk dipilih menjadi sampel. Metode yang digunakan adalah purposive sampling artinya hanya populasi yang memiliki kriteria tertentu yang diambil sebagaisampel. Kriteria dalam penelitian ini adalah karyawan kontrak yang bekerja pada perusahaan manufaktur di kawasan Panbil kota Batam.

\subsection{Teknik Pengumpulan Data}

Data yang digunakan dalam penelitian ini adalah data primer. Teknik pengumpulan data menggunakan metode survei dengan kuesioner, yaitu memberikan daftar pertanyaan atau pernyataan kepada responden untuk memperoleh informasi yang dibutuhkan dalam penelitian. Tipe skala pengukuran data yang digunakan adalah skala ordinal dengan skala likert 1 sampai 5, dengan bobot sebagai berikut : sangat tidak setuju diberi skor 1 , tidak setuju diberi skor 2, netral diberi skor 3 , setuju diberi skor 4, sangat setuju diberi skor 5 (Sugiyono, 2014).

\subsection{Teknik Pengolahan Data}

Sebelum melakukan analisis data, maka perlu dilakukan tahap-tahap teknik pengolahan data yaitu sebagai berikut: Editing yaitu proses memeriksa data yang sudah terkumpul, meliputi kelengkapan isian, keterbacaan tulisan, kejelasan jawaban, relevansi jawaban, dan sebagainya. Coding yaitu pemberian kode setiap data yang terkumpul pada instrumen penelitian, gunanya adalah untuk memudahkan dalam penganalisisan dan penafsiran data. Tabulasi yaitu mengelompokkan data yang sudah terkumpul dalam beberapa tabel agar mudah dipahami. Setelah proses tabulasi, maka dilakukan pengolahan menggunakan program komputer SPSS.

\section{HASIL}

Penelitian ini menggunakan karyawan kontrak pada perusahaan manufaktur yang berada di kawasan industri Panbil kota Batam sebagai responden. Dari 334 kuesoner yang di sebarkan, hanya 162 yang kembali.

Tabel 1

Karakteristik Responeden

\begin{tabular}{l|l|l}
\hline No & \multicolumn{1}{|c|}{ Jenis Kelamin } & Presentase \% \\
\hline 1 & Laki-laki & $24,6 \%$ \\
\hline 2 & Perempuan & $75,4 \%$ \\
\hline & Jumlah & $100 \%$ \\
\hline
\end{tabular}

\begin{tabular}{l|l|l}
\hline No & \multicolumn{1}{|c|}{ Usia } & \multicolumn{1}{|c}{ Persentase \% } \\
\hline 1 & $18-21$ tahun & $37,0 \%$ \\
\hline 2 & $22-25$ tahun & $50,0 \%$ \\
\hline 3 & Diatas 25 tahun & $13,0 \%$ \\
\hline & Jumlah & $100 \%$ \\
\hline
\end{tabular}

Tabel 1 menunjukkan karakter dari responden yang terdiri atas jenis kelamin dan usia. Hasil dari jenis kelamin menunjukkan bahwa perempuan lebih dominan dengan persentase $76,9 \%$, hal ini dikarenakan perempuan lebih teliti dan telaten dalam mengerjakan sesuatu. Usia rata-rata responden adalah antara 22-25 tahun, yang merupakan angka produktif dan matang dalam bekerja.

Tabel II

Hasil Analisis Regresi

\begin{tabular}{|c|c|c|c|c|c|}
\hline \multirow[t]{2}{*}{ Model } & \multicolumn{2}{|c|}{$\begin{array}{l}\text { Unstandandized } \\
\text { Coefficients }\end{array}$} & \multirow{2}{*}{$\begin{array}{c}\begin{array}{c}\text { Standardited } \\
\text { Coefficients }\end{array} \\
\text { Beta } \\
\end{array}$} & \multirow[t]{2}{*}{$t$} & \multirow[t]{2}{*}{ Sig } \\
\hline & B & Std. Error & & & \\
\hline 1 (Censtang) & 14,159 & 854 & & 16,972 &, 000 \\
\hline VARC0001 & -035 & 022 & -108 & $-1,580$ & 116 \\
\hline YAR00002 & 131 & .021 & 589 & 8,616 & .000 \\
\hline
\end{tabular}


Berdasarkan hasil olahan data, maka dapat dirumuskan persamaan regresi linear berganda sebagai berikut:

$\mathrm{Y}=14,155+(-0,035) \mathrm{X} 1+(-0,181) \mathrm{X} 2$

Interpretasi dari hasil tersebut adalah nilai konsistensi Y yatu 14,155 jika X1 dan X2 tetap (nilainya tidak berubah). Kepuasan keja menunjukkan hasil -0,035 yang berarti jika kepuasan kerja bertambah maka turnover intention akan berkurang sebesar -0,035, Komitmen organisasi menunjukkan hasil -0,181 yang berarti jika komitmen organisasi bertambah maka turnover intention akan berkurang sebesar -0,181.

\section{KESIMPULAN}

Turnover intention yang tinggi pada suatu perusahaan dapat mempengaruhi serta mengganggu kinerja perusahaan tersebut, karena banyak waktu serta materi yang terbuang untuk menyeleksi serta melatih karyawan baru.Mempertimbangkan hal tersebut, peneliti merasa perlu untuk melakukan penelitian lebih lanjut terkait kepuasan kerja dan komitmen organisasi terhadap turnover intention.

Berdasarkan penelitian terdahulu, peneliti dapat menarik dua hipotesis yang dimulai dari penyebaran terhadap 162 responden pada karyawan kontrak yang berada di kawasan industri Panbil kota Batam, yang selanjutnya data diolah dengan menggunakan alat statistik SPSS dan menghasilkan kesimpulan sebagai berikut;

Pertama, kepuasan kerja tidak berpengaruh terhadap turnover intention.Masih ada karyawan yang merasa tidak puas dengan pekerjaan ataupun perusahaan namun ingin tetap tinggal atau tetap bekerja pada perusahaan tersebut. Berdasarkan hasil pengamatan terhadap situasi kerja di kota Batam, karyawan tentu masih membutuhkan pekerjaan walaupun pada kenyataannya mereka tidak puas dengan pekerjaan atau perusahaannya, hal ini dikarenakan semakin sulitnya mencari pekerjaan baru.

Kedua, semakin tinggi komitmen organisasi seseorang terhadap perusahaan, maka turnover intention akan semakin rendah yang artinya sangat penting sebuah komitmen terhadap perusahaan tersebut, karyawan menganggap bahwa perusahaan atau pekerjaan mereka merupakan hal yang penting untuk kehidupannya.

\section{Keterbatasan}

Penelitian ini hanya terbatas pada karyawan kontrak dan hanya di kawasan industri Panbil kota Batam saja, mungkin jika dilakukan di seluruh kota Batam hasilnya akan lebih signifikan.

\section{Implikasi dan Saran}

Penelitian ini diharapkan mampu menjadi salah satu informasi bagi perusahaan untuk mengurangi tingkat turnover intention yang akan terjadi, serta mampu menjadi rujukan untuk pengambilan keputusan terkait kebijakan-kebijakan yang akan dikeluarkan perusahaan untuk karyawannya.

Berdasarkan hasil yang diperoleh bahwa tidak ada hubungan antara kepuasan kerja dan turnover intention, artinya ada variabel lain yang tidak diteliti yang lebih berpengaruh terhadap turnover intention. Hasil untuk komitmen organisasi adalah signifikan terhadap turnover intention, artinya komitmen organisasi cukup mempengaruhi tingat turnover intention karyawan. Perusahaan harus meningkatkan komitmen karyawannya seperti dengan penambahan insentif atau penambahan kepedulian terhadap karyawan dengan jaminan kesehatan, keselamatan kerja atau rekreasi rutin untuk para karyawan.

Penelitian selanjutnya dapat menambah variabel lain yang belum ada pada penelitian ini serta men generalisasikan karyawan yang ada pada perusahaan tersebut, artinya tidak hanya karyawan kontrak atau tetap saja. Memperhatikan tingkat pendidikan terakhir karyawan serta gaji yang diperolehnya.

\section{DAFTAR REFERENSI}

[1] Ajzen. (1988). Teori Intensi. Academia Web Site.

[2] APPLEBAUM, D. H. (2008). the relationship between physical work environmenal factors, perceived stess, job satisfaction and turnover intention among inpatient acute care nurses. UMI Microform 3323284, 17.

[3] Bajwa, E. U., Yousaf, M., \& Rizwan, M. (2014). Employee Turnover Intention in services sector of Pakistan. International Journal of Human Resource Studies, 2162-3058.

[4] Brehm, \& Kassin. (1990). Teori Intensi. Academia Web Site.

[5] Fawzy, A. G. (2012). Pengaruh Stres Kerja, Kepuasan Kerja Dan Komitmen Karyawan.

[6] Fu, W., \& Deshpande, S. P. (2014). The Impact of Caring Climate, Job Satisfaction, and Organizational Commitment on Job Performance of Employees in a China's Insurance Company. J Bus Ethics, 339-349.

[7] Golan, A. C. (2007). Predicting absenteeism and turnover intentions by past absenteeism and work attitudes An empirical examination of female employees in long term nursing care facilities. Career Development International, 12, 416-432.

[8] Holland, C. B. (1992). The influence of job satisfaction and organizational commitment on inten tion to leave o $f$ nurse educators. University Microfilms International.

[9[ Kholid, A. (t.thn.). About Us: Academia. Dipetik June 4, 2016, dari Academia Web Site: https://www.academia.edu/4433491/Teori_Intensi

[10] Liou, S.-R. (2007). The Relationships between Collectivist Orientation, Perception of Practice Environment, 
Organizational Commitment, and Intention to Leave Current Job among Asian Nurses Working in the U.S. UMI Microform 3277553 .

[11] Luthans, F. (2006). Perilaku Organisasi (Vol. 10). (S. Purwanti, Penyunt., V. Andhika, S. Purwanti, T. A. P, \& W. Rosari, Penerj.) Yogyakarta: ANDI.

[12] Mahdi, 1. F., \& 2Mohamad Zaid Mohd Zin, 3. R. (2012). The Relationship Between Job Satisfaction and Turnover Intention. American Journal of Applied Sciences, 1518-1526.

[13] Nandini, N., \& Rochmah, T. N. (2013). Penyebab Turnover Intention Pada Pegawai Instalasi Gizi Rumah Sakit Phc Surabaya. Jurnal Administrasi Kesehatan Indonesia, 1.

[14] Nazenin, S., \& Palupiningdyah. (2014). Peran Stres Kerja Dan Kepuasan Kerja Untuk Mengurangi Turnover Intention. Jurnal Dinamika Manajemen, 220-227.

[15] Putra, I. G., \& Wibawa, I. M. (2015). Pengaruh Kepuasan Kerja Terhadap Turnover Intention Dengan Komitmen Organisasi Sebagai Variabel Intervening Pada Pt. Autobagus Rent Car Bali. E-Jurnal Manajemen Unud, 4, 1100-1118.

[16] Sugiyono. (2014). Metode Penelitian Manajemen. Bandung: Alfabeta, CV.

[17] Sunyoto, D. (2015). Penelitian Sumber Daya Manusia. Yogyakarta: CAPS (Center of Academic Publishing Service.

[18] Warner, T. H. (2001). The Effects Of Job Satisfaction And Organizational Commitment On Intent To Leave Among Nurse Anesthetists. Umi Microform 9998847.

[19] Widyantara, I. B., \& Ardana, I. K. (2015). Pengaruh Kepuasan Kerja Dan Komitmen Organisasi Terhadap Intensitas Turnover Karyawan. E-Jurnal Manajemen Unud, 4, 1670-1683. 